\title{
Assessment of the Operating Temperature of Crystalline PV Modules Based on Real Use Conditions
}

\author{
Giuseppina Ciulla, Valerio Lo Brano, Vincenzo Franzitta, and Marco Trapanese \\ DEIM Dipartimento di Energia, Ingegneria dell'Informazione e Modelli Matematici, Università degli Studi di Palermo, \\ Viale delle Scienze Edificio 9, 90128 Palermo, Italy \\ Correspondence should be addressed to Giuseppina Ciulla; ina@dream.unipa.it
}

Received 16 October 2013; Revised 10 February 2014; Accepted 12 February 2014; Published 10 April 2014

Academic Editor: Niyaz Mohammad Mahmoodi

Copyright (C) 2014 Giuseppina Ciulla et al. This is an open access article distributed under the Creative Commons Attribution License, which permits unrestricted use, distribution, and reproduction in any medium, provided the original work is properly cited.

\begin{abstract}
Determining the operating temperature $T_{c}$ of photovoltaic panels (PV) is important in evaluating the actual performance of these systems. In the literature, different correlations exist, in either explicit or implicit forms, which often do not account for the electrical behaviour of panels; in this way, estimating $T_{c}$ is based only on the passive behaviour of the PV. In this paper, the authors propose a new implicit correlation that takes into account the standard weather variables and the electricity production regimes of a PV panel in terms of the proximity to the maximum power points. To validate its reliability, the new correlation was tested on two different PV panels (Sanyo and Kyocera panels) and the results were compared with values obtained from other common correlations already available in the literature. The data show that the quality of the new correlation drastically improves the estimation of the photovoltaic operating temperature.
\end{abstract}

\section{Introduction}

According to Clean Energy Reports 2012 [1], the renewable energy market, which includes solar photovoltaic, wind power, and biofuels, grew 31 percent last year, reaching $\$ 246.1$ billion. In detail, the solar photovoltaic market (including modules, system components, and installation) increased globally, from $\$ 71.2$ billion in 2010 to a record $\$ 91.6$ billion in 2011. Nevertheless, the year 2011 will be remembered for the infamous Solyndra bankruptcy. The failed company, a manufacturer of innovative cylindrical PV panels, became "proof" that clean and renewable technologies cannot compete without subsidies and government regulations. From the point of view of the designers and end-users of PV systems, the availability of reliable building software tools is essential for evaluating energy efficiency, renewable energy, and sustainability [2-5]. Furthermore, because buildings account for approximately $40 \%$ of the primary energy consumption and $70 \%$ of the electricity consumption in OECD countries [6], the use of photovoltaic to achieve net-zero energy buildings has been highly promoted [7]. It is well known that predictive performance tools are important factors in the success of any technology; the ability to optimise the performance of a PV system allows consumers to maximize the costeffectiveness of the system before installation. Indeed, the whole-building energy performance simulation tools could demonstrate whether a renewable energy system will be economically sustainable [8].

In general, the performance of a photovoltaic panel is defined according to the "peak power," which identifies the maximum electric power supplied by the panel when it receives an insolation of $1 \mathrm{~kW} / \mathrm{m}^{2}$ at a cell temperature of $25^{\circ} \mathrm{C}$. These conditions are only nominal because the insolation has a variable intensity and the panel is subjected to considerable temperature changes [7].

Two important parameters of the $I-V$ curve for a PV module are the short-circuit current $I_{\mathrm{sc}}$ and the open-circuit voltage $V_{\text {oc }}$ that change with the solar irradiance and with the ambient air temperature [9]. In Andreev et al. [10] it has been shown that the photocurrent increases with the temperature at $0.1 \%{ }^{\circ} \mathrm{C}^{-1}$ due to the decrease of the gap of the solar cell and that the open-circuit voltage decreases at $-2 \mathrm{mV}^{\circ} \mathrm{C}^{-1}$ between 20 and $100^{\circ} \mathrm{C}$ not only due to a reduction of the gap, but also 
due to an increase of the saturation current. These two effects lead to a decrease for the maximum available power equal to $0.35 \%{ }^{\circ} \mathrm{C}^{-1}$. More recently, this influence has been estimated between -0.3 and $-0.5 \%{ }^{\circ} \mathrm{C}^{-1}[11-14]$. It is obvious that these influences on $I_{\mathrm{sc}}$ and $V_{\mathrm{OC}}$ have some consequences on the electrical efficiency of the PV cell or module.

As it is resumed by Skoplaki and Palyvos [19], many correlations for predicting the electrical performance of a PV module have been proposed and used by several authors. These relations especially emphasize the role of the silicon temperature that considered the main parameter affecting the conversion efficiency. The expression proposed by Evans [20] to describe the module's efficiency $\eta$ in correspondence of given values of the operating temperature $T_{c}$ and insolation $G$ is well known:

$$
\eta=\eta_{\text {ref }}\left[1-\chi\left(T_{c}-25\right)+\varepsilon \log _{10}\left(\frac{G}{G_{\text {ref }}}\right)\right],
$$

on the basis of $\eta_{\text {ref }}$, which is the efficiency at Standard Test Conditions (STC) in which the solar irradiance $G_{\text {ref }}$ is $1000 \mathrm{~W} / \mathrm{m}^{2}$ and the temperature of the cell $T_{c}$ is $25^{\circ} \mathrm{C}$. The temperature coefficient $\chi$ and the insolation coefficient $\varepsilon$ have values of $0.004 \mathrm{~K}^{-1}$ and 0.12 , respectively, for crystalline silicon modules [21]. Other correlations, which have been recently proposed in Mattei et al. [9], Koehl et al. [22], and Skoplaki and Palyvos [23], use empirical constants whose values only refer to few models of PV panels.

In Faiman [24], the energy balance is based upon a simplified heat transfer formalism that was originally developed for flat-plate solar-thermal collectors under conditions of steady state, namely, the so-called Hottel-Whillier-Bliss equation; the module temperatures is correlated with ambient temperature, wind speed, plane-of-array solar irradiance, and a pair of experimental heat loss coefficients.

The cell temperature appears, thus, to be an important parameter to study; indeed the operating temperature of the cell $T_{c}$ is one of the most important parameters in determining the energy conversion efficiency of a PV panel: the efficiency of a PV device is a decreasing function of the $T_{c}$ temperature (1). In the literature, there are several available empirical correlations to obtain the PV panel operating temperature, where these correlations have been developed for common geometries and standard weather variables. From a mathematical point of view, the correlations for the PV operating temperature are either explicit in form, thus giving $T_{c}$ directly, or implicit in form; that is, they involve variables which depend on $T_{c}$; in the last case, an iteration procedure is necessary for the calculation. Most of the correlations typically include the reference condition and the corresponding values of the pertinent variables [23].

The most common procedure to determine the cell temperature $T_{c}$ consists in using the Normal Operating Cell Temperature (NOCT) [25-27]. The value of this parameter is given by the PV module manufacturer: $T_{c}$ is then dependent on the ambient temperature $T_{a}$ and on the ratio of insolation $\mathrm{G}\left[\mathrm{W} / \mathrm{m}^{2}\right]$ to the standard value of $800 \mathrm{~W} / \mathrm{m}^{2}$, according to

$$
T_{c}=T_{a}+\left(T_{\mathrm{NOCT}}-20\right) \frac{G}{800} \text {. }
$$

This very simple method yields satisfying results if the PV modules are not roof-integrated. A complete definition of NOCT and the conditions of determination of this parameter are presented in [28] and in [29, 30]. But the NOCT approach, and many of those available in the literature, estimates $T_{c}$ based only on the passive behaviour of the PV, not taking into account at the same time the standard weather variables and the electricity production regimes of the PV module. Indeed it is well known that most of the solar irradiance absorbed by a photovoltaic panel is not converted to electricity but contributes to increase its temperature, thus reducing the electrical efficiency. The typical power curve of a commercial $\mathrm{PV}$ module always contains a single maximum, and in the aforementioned defined standard conditions, approximately only $15 \%$ of the incident solar energy is converted into electricity; the remaining part of the insolation is transformed into heat. The heat transfer between the PV panel and the surrounding environment is driven by a global heat transfer coefficient, which describes the radiative and convective exchange processes.

Standard parameters in PV systems such as final energy yield (YF) or performance ratio (PR) can be calculated following the definitions coded in IEC 61724. These parameters are simply calculated as sums (YF) or averages (PR) of the $\mathrm{PV}$ device performance over the measurement period and therefore do not allow for correlations with parameters such as solar irradiance, temperature, or downtime. For a better characterization and prediction of PV module performance under outdoor conditions, detailed studies on the level of $I-V$ parameters would be desirable [31]. To predict the yield of a photovoltaic system, it is essential to evaluate the operating condition under all possible circumstances of insolation, panel temperature, wind speed, air temperature, electric load $R_{L}$, and the time the photovoltaic elements are working and producing electricity [32]. The availability of a large amount of experimental data can give the possibility to build numerical model that applies several new techniques based on artificial intelligence to predict the operating temperature of a PV module. Recently, this methodology has received attention and its use increased very successfully [33-39]. These methods can work with vague inputs and can handle nonlinearities but, at the same time, do not issue an exact mathematical model and require a notable calculating capacity.

For given values of insolation, temperature, and electrical load, the operating point can be identified by drawing lines of the different loads $R_{L}$ on the $I-V$ characteristic.

In Figures 1 and 2, it is possible to observe how the intersection between the load line and PV characteristic corresponds to the working point; with the same graphical method, it is possible to identify the working point in terms of electric power.

The aim of this paper is to identify a correlation that links the weather variables such as solar irradiance, air temperature, and wind speed to the operative PV temperature taking into account its actual power production regimes. This correlation should permit the implementation of simulation tools to avoid a thermal balance of the panel with the 


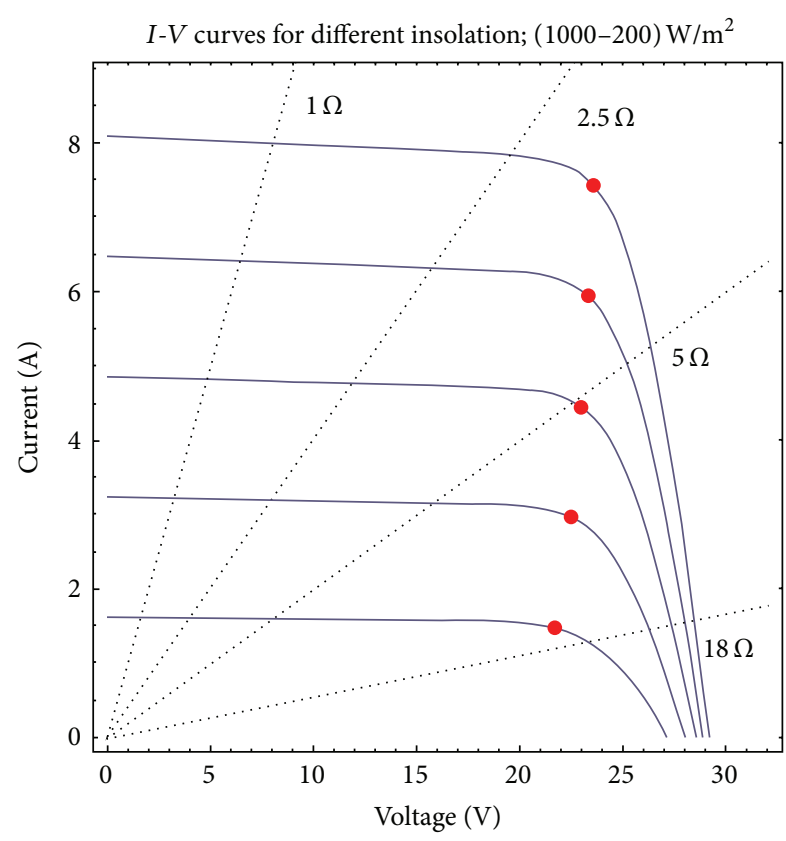

FIGURE 1: Working point of a generic PV panel at constant temperature $\left(25^{\circ} \mathrm{C}\right)$ varying insolation and electric load.

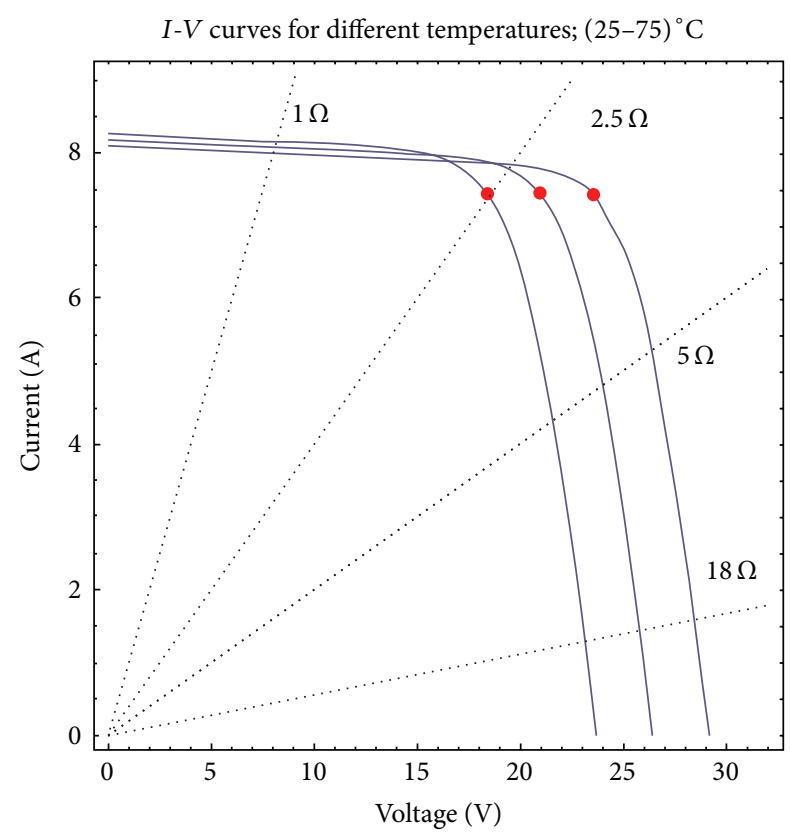

FIGURE 2: Working point of a generic PV panel at constant insolation $\left(1000 \mathrm{~W} / \mathrm{m}^{2}\right)$ varying temperature and electric load.

surrounding environment in the deployment of simulation tools.

\section{Electricity Production Regimes of a PV Panel}

As it was previously described, the PV operating temperature greatly influences the yield of electrical conversion. This yield decreases dramatically as the temperature increases, which in most cases occurs when the panel is subjected to the maximum insolation. This negative temperature effect is a weakness in PV technology, and the data provided by the manufacturers are generally insufficient for reliable evaluation. Typically, only the most accurate technical sheets provide temperature coefficients that relate only to shortcircuit and open-circuit conditions.

The analysis of the common current-voltage curves given by manufactures at constant temperature or constant insolation does not allow a correct evaluation of the thermoelectrical behaviour of a photovoltaic panel because, in actual conditions, the temperature and the insolation change simultaneously. Furthermore, the effectiveness of solar energy conversion into electrical energy is influenced by the operation mode of the panel. It is easy to verify in Figure 3 that the electrical characteristics of the panel with varying insolation tend to overlap in a region characterised by high values of load (dashed blue circles in Figure 3). In these regions, the panel is subjected to the saturation phenomenon, and thus, considerable insolation variations do not cause large variations in energy production.

To better understand the change of the electrical behaviour of a PV panel varying climatic conditions and electric load, some trends of the power production of a Kyocera KC175GHT-2 panel located in the city of Palermo (Italy) are showed. Two different conditions are represented in detail: the power production of the panel connected to an electrical load of $R_{L}=1 \Omega$ and the power production of the panel connected to an electrical load of $R_{L}=18 \Omega$.

Indeed in the first case, as represented in Figure 4, the electrical load of $R_{L}=1 \Omega$ drives the panel to work in a regime far away from the saturation condition. It is immediately clear that there is a quasilinear correlation between the power output and the insolation; in these conditions the power is maximum when there is the maximum insolation. In contrast, in Figure 5, the same panel is connected to an electrical load of $R_{L}=18 \Omega$ that achieves the saturation condition; the panel during the most sunny period becomes insensitive to insolation variations. At saturation conditions, the panel delivers the same power output, and from a thermal point of view, the temperature of the panel must increase to discharge the heat to the environment, as explained by the following simple heat balance:

$$
P_{\text {ele }}=\tau \alpha G-P_{\text {panel }},
$$

where $P_{\text {ele }}$ represents the power output produced by the panel (W); $\tau$ is the transmissivity coefficient of the glass of the panel; $\alpha$ is the absorptance coefficient of the silicon layer of the panel; $P_{\text {panel }}$ is sum of three terms: the thermal power dissipated by convection into the surrounding environment, the thermal power dissipated by radiation, and the thermal power that contributes to changing the temperature of the entire module. 


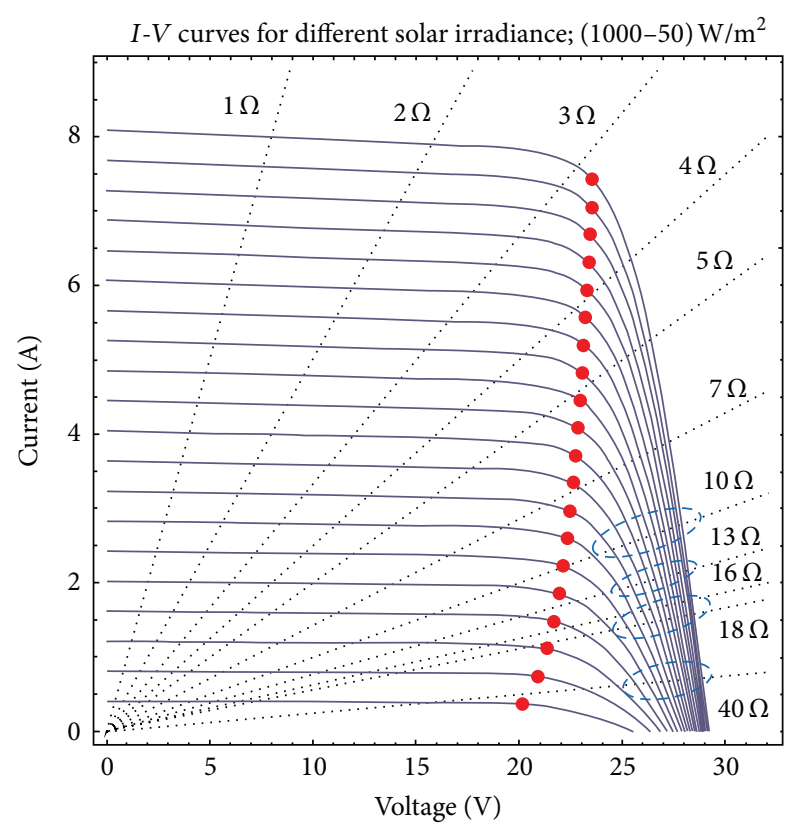

Figure 3: $I-V$ curves of a PV panel at constant temperature $\left(25^{\circ} \mathrm{C}\right)$ and electric load lines. Red points indicate maximum power and blue dashed circles indicate overlap regions where module is in saturation conditions.

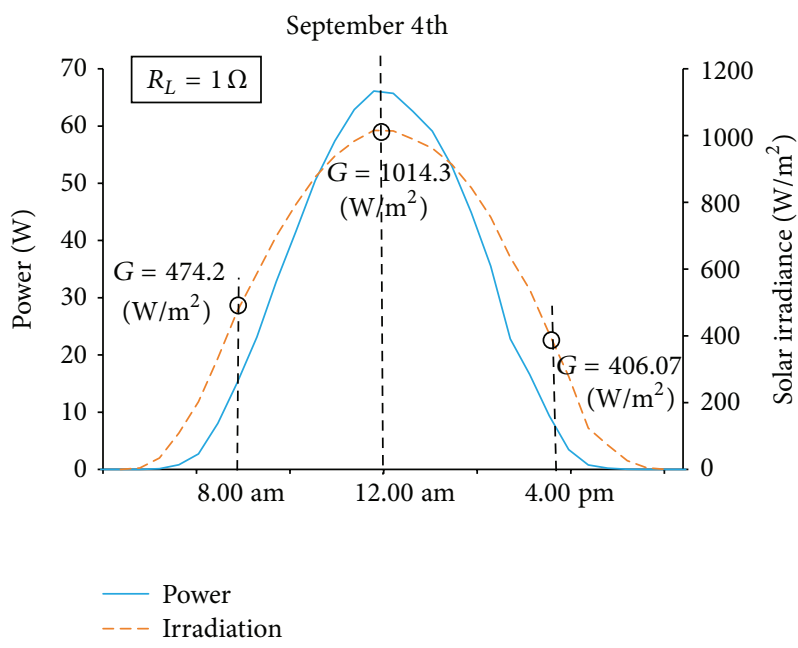

FIgURE 4: Power production of a PV panel with an electrical load $R_{L}$ $=1 \Omega$.

In summary, Figures 3-5 highlight that the electrical behaviour of the PV module is really different when the module is working in different operating regimes. If the panel is connected to an optimized and variable electrical load (with a maximum power point tracking system), the output power is quasilinear to solar irradiance. If the MPPT device is not present, depending on the connected electric load, the relation between power output and solar irradiance could be no longer linear. Such complexity affects even the thermal behaviour of the module, as described by (3).

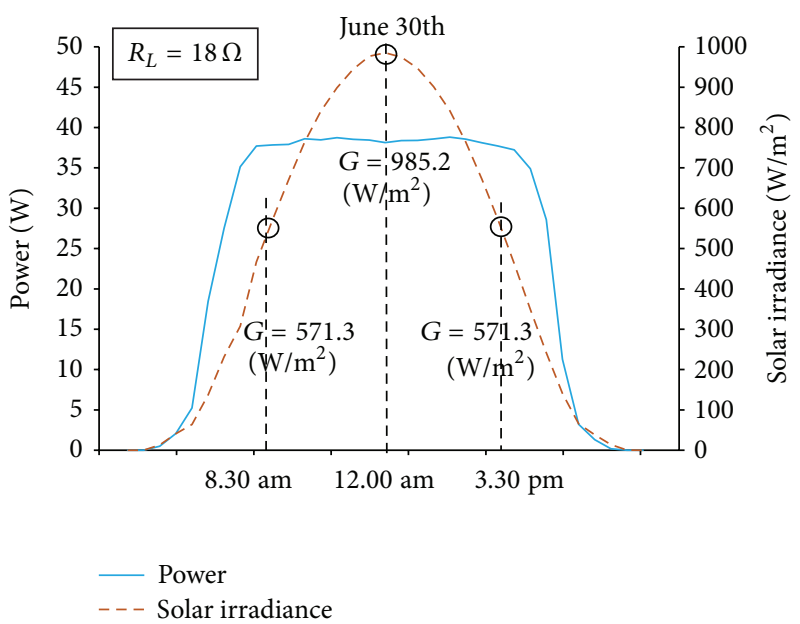

Figure 5: Power production of a PV panel with an electrical load $R_{L}$ $=18 \Omega$.

\section{Identification of Operation Regimes}

As already written, the maximum electrical power produced by a PV device not only is linked to the solar irradiance on the panel and to the cell temperature but also depends on connected electrical load $R_{L}$ as shown in Figures 1 and 2 . In previous works $[40,41]$ the authors have investigated and refined a procedure more and more reliable, based on the onediode equivalent circuit, for the modelling of the electrical behaviour of the photovoltaic cell, issuing the following equation:

$$
\begin{aligned}
& I\left(\alpha_{G}, T\right) \\
& =\alpha_{G} I_{L}(T)-I_{0}\left(\alpha_{G}, T\right) \\
& \quad \times\left(e^{\left(\alpha_{G}\left[V+K \cdot I\left(T-T_{\mathrm{ref}}\right)\right]+I \cdot R_{s}\right) / \alpha_{G} n T}-1\right) \\
& \quad+\frac{\alpha_{G}\left[V+K \cdot I\left(T-T_{\mathrm{ref}}\right)\right]+I \cdot R_{s}}{\alpha_{G} R_{\mathrm{sh}}},
\end{aligned}
$$

in which $I_{L}$ is the photocurrent and it depends on the solar irradiance, $I_{0}$ is the diode reverse saturation current and is affected by the silicon temperature, $n$ is the ideality factor and $T$ is the cell temperature in Kelvin, $R_{\text {sh }}$ is the shunt resistance, $R_{s}$ is series resistance, the quantity $\alpha_{G}=G / G_{\text {ref }}$ denotes the ratio between the generic solar irradiance and the irradiance at STC $\left(1000 \mathrm{~W} / \mathrm{m}^{2}\right)$, and $K$ is a thermal correction factor similar to the curve correction factor described by the IEC 891 [42]. Equation (4) is able to represent the $I-V$ characteristics in correspondence of irradiance and temperature values far from the STC. The graphical representation of the $I-V$ curve described by (4) with the variation of $\alpha_{G}=G / G_{\text {ref }}$ from 1000 to $50 \mathrm{~W} / \mathrm{m}^{2}$ (Figure 6 ) permits easily identifying a correlation between $\alpha_{G}$ and the maximum power point voltage $V_{\text {mpp}}$.

The application of the model presented in Lo Brano and Ciulla [41] to the Kyocera KC175GHT-2 panel, characterized by the data reported in Table 1 , allowed us to calculate the maximum power point voltage $V_{\text {mpp }}$ related to several values of solar irradiance grouped in Table 2. 


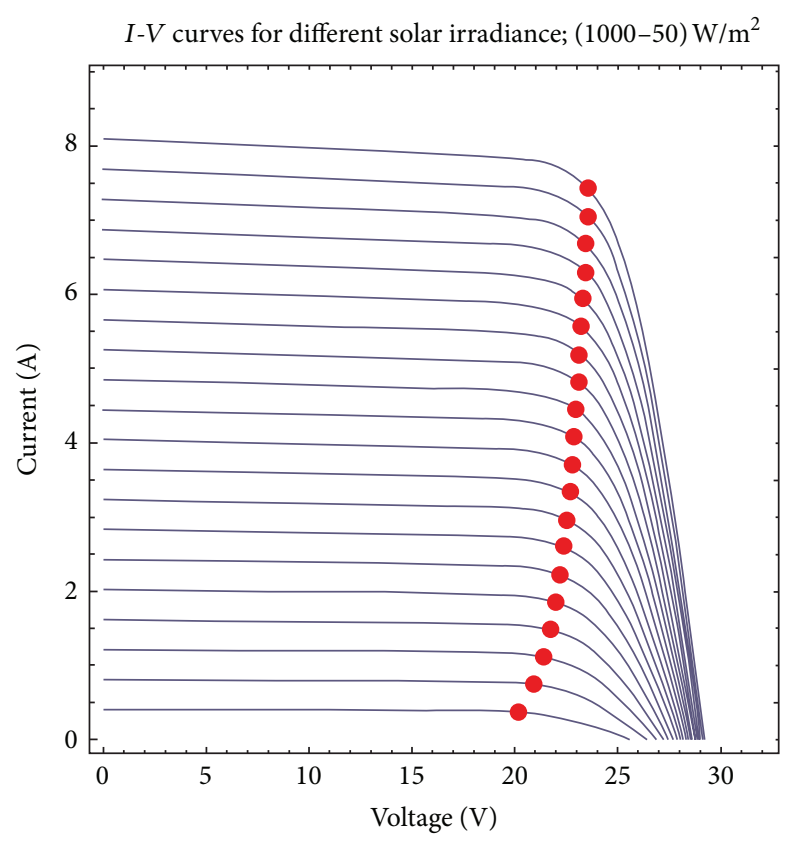

(a)

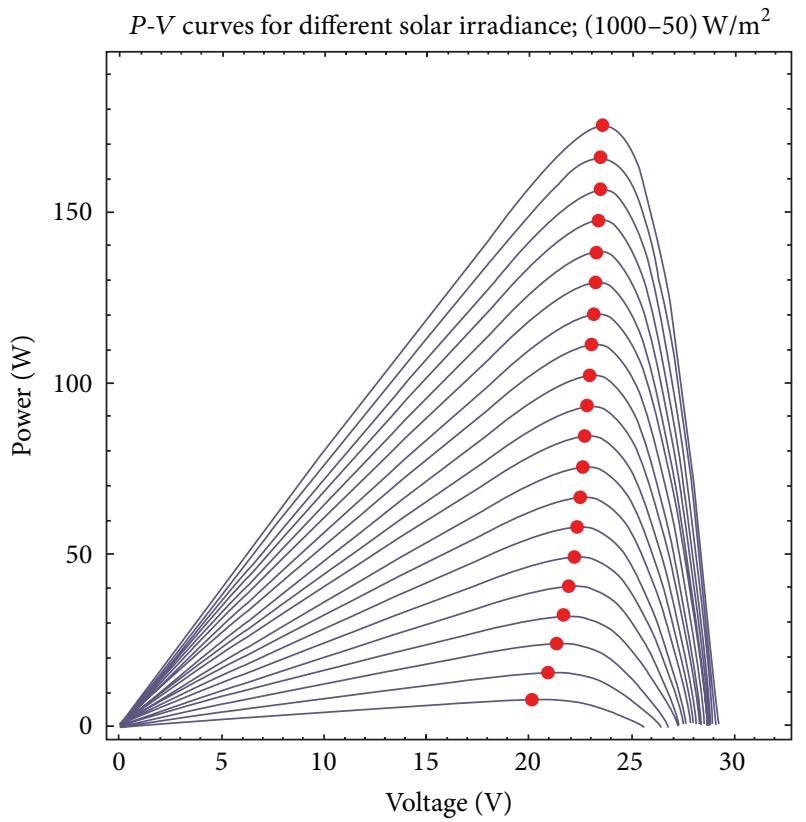

(b)

FIGURE 6: Position of maximum power points (red circles) of Kyocera KC175GHT-2 with variation of solar irradiance calculated with (4).

TABLE 1: Thermoelectrical features of the Kyocera KC175GHT-2 at STC.

\begin{tabular}{lcc}
\hline Maximum power & $P_{\max }(\mathrm{W})$ & 175 \\
Maximum voltage & $V_{\mathrm{mpp}}(\mathrm{V})$ & 23.6 \\
Maximum current & $I_{\mathrm{mp}}(\mathrm{A})$ & 7.42 \\
Open circuit voltage & $V_{\mathrm{oc}}(\mathrm{V})$ & 29.2 \\
Short circuit current & $I_{\mathrm{sc}}(\mathrm{A})$ & 8.09 \\
Thermal voltage coefficient & $\mu_{V_{\mathrm{oc}}}\left(\mathrm{V} /{ }^{\circ} \mathrm{C}\right)$ & -0.109 \\
Thermal current coefficient & $\mu_{I_{\mathrm{sc}}}\left(\mathrm{mA} /{ }^{\circ} \mathrm{C}\right)$ & 3.18 \\
Thermal correction factor & $\mathrm{K}\left(\Omega /{ }^{\circ} \mathrm{C}\right)$ & -0.0008753 \\
\hline
\end{tabular}

The parametric analysis of the results coming from (4) and reported in Table 2 allows extrapolating a simple logarithmic correlation between the maximum power point voltage $V_{\mathrm{mpp}}$ and the solar irradiance $G$ as shown in Figure 7:

$$
V_{\mathrm{mpp}}=1.1686617 \cdot \ln \left(\alpha_{G}\right)+23.5974267
$$

with Pearson correlation coefficient $R^{2}=0.9999958$.

The analysis of the results obtained by applying a logarithmic regression on the values grouped in Table 2 allows the following considerations:

(1) the high value of the Pearson correlation coefficient fully confirms the reliability of the assumed logarithmic correlation between $\alpha_{G}$ and $V_{\text {mpp }}$;

(2) the degree zero term of the logarithmic correlation is very close to $V_{\text {oc }}$ value at STC;

(3) the factor that multiplies the logarithmic term is very close to the value of the $n T$ parameter.

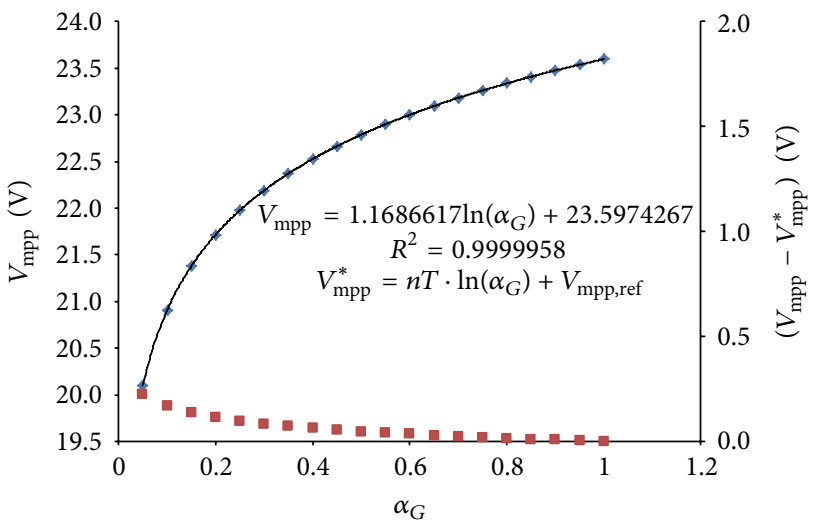

FIGURE 7: Extrapolation of a logarithmic correlation between $V_{\text {mpp }}$ and the solar irradiance $G$.

In order to provide an immediate correlation for the value of $V_{\text {mpp }}$ with the variation of $G$, the authors propose the following approximate formula:

$$
V_{\mathrm{mpp}} \cong V_{\mathrm{mpp}}^{*}=n T \cdot \ln \left(\alpha_{G}\right)+V_{\mathrm{mpp}, \mathrm{ref}}
$$

Indeed, in Figure 7 the blue points represent the voltage values at maximum power point conditions $V_{\mathrm{mpp}}$ with the variation of solar irradiance in terms of ratio of current irradiance to $1000 \mathrm{~W} / \mathrm{m}^{2}$ (standard rating conditions). If we assume a logarithmic correlation between $V_{\text {mpp }}$ and solar irradiance, applying a least-squares regression, it is possible to obtain (5). The red points represent the difference between the $V_{\text {mpp }}$ calculated by (5) and the $V_{\mathrm{mpp}}^{*}$ calculated by the empirical correlation represented by (6), already known in 
TABLE 2: Tabular data of $I-V$ curve of the Kyocera KC175GHT-2 at different solar irradiance.

\begin{tabular}{lccccccccccc}
\hline Rad. $\left(\mathrm{W} / \mathrm{m}^{2}\right)$ & 1000 & 900 & 800 & 700 & 600 & 500 & 400 & 300 & 200 & 100 \\
\hline$P_{\max }(\mathrm{W})$ & 175.1 & 156.8 & 138.5 & 120.3 & 102.3 & 84.5 & 66.8 & 49.3 & 32.1 & 15.5 & 7.4 \\
$V_{\max }(\mathrm{V})$ & 23.6 & 23.5 & 23.3 & 23.2 & 23.0 & 22.8 & 22.5 & 22.2 & 21.7 & 20.9 & 20.1 \\
$I_{\max }(\mathrm{A})$ & 7.4 & 6.7 & 5.9 & 5.2 & 4.4 & 3.7 & 3.0 & 2.2 & 1.5 & 0.7 & 0.4 \\
$V_{\text {oc }}(\mathrm{V})$ & 29.2 & 29.1 & 28.9 & 28.8 & 28.6 & 28.3 & 28.1 & 27.7 & 27.2 & 26.3 & 25.5 \\
$I_{\mathrm{sc}}(\mathrm{A})$ & 8.1 & 7.3 & 6.5 & 5.7 & 4.9 & 4.0 & 3.2 & 2.4 & 1.6 & 0.8 & 0.4 \\
\hline
\end{tabular}

the bibliography. The risible difference observed between the values $V_{\mathrm{mpp}}$ and $V_{\mathrm{mpp}}^{*}$ permits using (6) instead of (5) to retrieve the value of $V_{\mathrm{mpp}}$ for each generic panel.

To identify the operation regimes of the panel as a function of electricity production regimes, the authors chose to compare the operating voltage $V$ with the maximum power point voltage $V_{\text {mpp,panel }}$ for a given insolation and temperature. In this way, the ratio $V / V_{\text {mpp,panel }}$ easily allows the operating regimes of the panel to be characterised:

(i) when the ratio between the working voltage $V$ and the voltage of maximum power $V_{\text {mpp,panel }}$ is less than 0.95 , the $I-V$ characteristic is almost horizontal, and the power output is proportional to the incident insolation;

(ii) when the ratio $V / V_{\text {mpp,panel }}$ is greater than 1.05 , the $I-V$ characteristic of the panel decreases much more rapidly and the influence of insolation becomes less significant (saturation conditions);

(iii) the regimen identified by a ratio $0.95<V / V_{\text {mpp,panel }}<$ 1.05 characterises the state of a PV panel connected to a MPPT in which the load dynamically adapts to generate the maximum power.

The author observed a relationship between the $V_{\text {mpp,panel }}$ and the insolation and temperature. The analysis of the graphical $I-V$ characteristics provided by the manufacturer enables one to obtain the $V_{\text {mpp,panel }}$ points for five different insolation values at a constant temperature of $25^{\circ} \mathrm{C}$ (Figure 1) and three points of maximum power for three different temperatures at a constant insolation of $1000 \mathrm{~W} / \mathrm{m}^{2}$ (Figure 2). With these points known, it is possible to extrapolate the $V_{\text {mpp,panel }}$ values in the following forms:

$$
\begin{aligned}
V_{\text {mpp,panel }}\left(G, 25^{\circ} \mathrm{C}\right) & =V_{\text {mpp,ref }}+\frac{a \ln (G / 1000)}{G^{b}}, \\
V_{\text {mpp,panel }}\left(1000 \mathrm{~W} / \mathrm{m}^{2}, T_{c}\right) & =V_{\text {mpp,ref }}+\mu_{T}\left(T_{c}-25\right),
\end{aligned}
$$

where $a$ and $b$ are two constants, which are different for each considered panel and are obtained by applying the leastsquares method to five $V_{\text {mpp }}$ points (red points in Figure 2) in correspondence of five values of insolation; $\mu_{T}$ is the thermal coefficient of the open-circuit voltage $\left[\mathrm{V} /{ }^{\circ} \mathrm{C}\right]$.

This simple procedure permits obtaining the variation of $V_{\text {mpp }}$ points for each considered PV panel; of course for different panel there will be a different couple of $(a, b)$ values.
Applying this methodology to the Kyocera panel, the authors obtained the following results:

$$
(a ; b)_{\text {Kyocera }}=(1.2425 ; 0.0113)
$$

that, as shown in the graphs of Figures 6 and 7, well approximates the $V_{\mathrm{mpp} \text {,Kyocera }}$ values:

$$
V_{\text {mpp,Kyocera }}\left(G, 25^{\circ} \mathrm{C}\right)=23.6+\frac{1.2425 \cdot \log (G / 1000)}{G^{0.0113}}
$$

the value of the thermal drift is issued by manufacturer, so equation (8) becomes:

$$
V_{\text {mpp,Kyocera }}\left(1000 \mathrm{~W} / \mathrm{m}^{2}, T_{c}\right)=23.6-0.108926 \cdot\left(T_{c}-25\right) \text {. }
$$

In detail, for a generic PV panel subjected simultaneously to changes in temperature and insolation, on the basis of the previous considerations, the $V_{\text {mpp,panel }}$ value can be obtained by the following formula:

$$
V_{\text {mpp,panel }}\left(G, T_{c}\right)=V_{\text {mpp,ref }}+\frac{a \ln (G / 1000)}{G^{b}}+\mu_{T}\left(T_{c}-25\right) .
$$

To investigate a correlation between the ratio $V / V_{\text {mpp }}$ and the photovoltaic operating temperature, the authors used data monitored in the field from two different PV panels.

\section{Experimental Apparatus}

To obtain a correlation that describes the actual photovoltaic operating temperature, we analysed experimental data collected during a monitoring campaign. The experimental system (Figure 8) was installed on the roof of the Energy Department in Palermo and consisted of the following equipment:

(i) two photovoltaic panels: Kyocera KC175GHT-2 and Sanyo HIT 240 HDE-4 modules;

(ii) a precision resistance set;

(iii) a multimeter Fluke189/FVF2;

(iv) a Delta Ohm pyranometer mod. LP PYRA $02 \mathrm{AV}$ linked to a data transducer;

(v) an Advantech ADAM 6024 module;

(vi) a Davis Vantage PRO2 Plus Weather station: the monitoring system for the weather variables is explained in more detail in Lo Brano et al. [43]. 

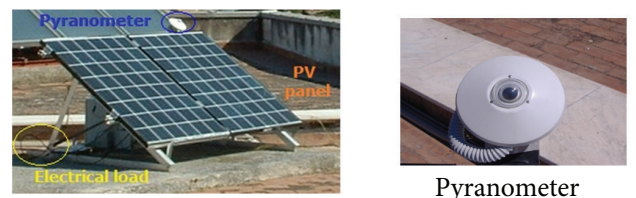

Pyranometer

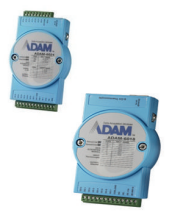

ADAM

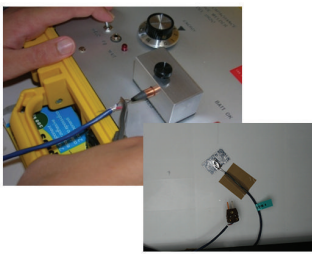

Thermocouples

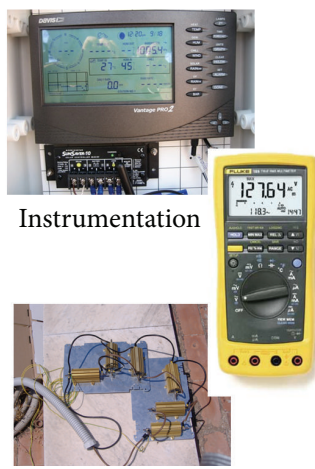

Electrical load

FIgURE 8: Experimental apparatus.

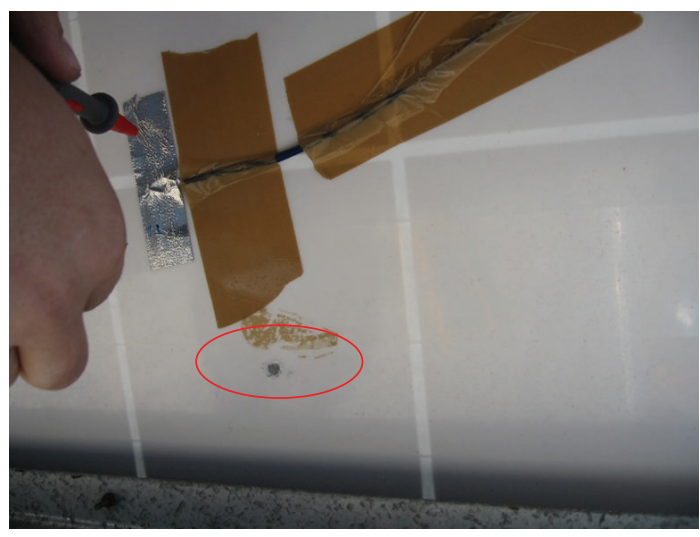

(a)

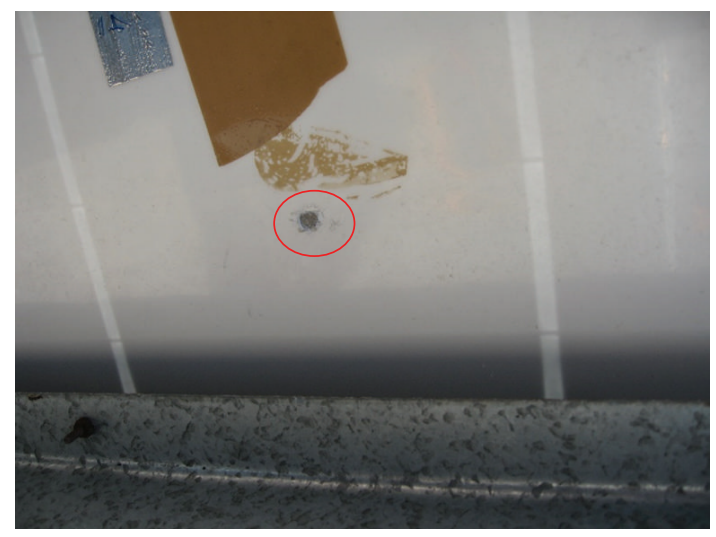

(b)

FIGURE 9: Experimental apparatus: little holes in the PET film of the PV panel to measure the temperature.

The PV panels and the pyranometer were tilted at an angle that is equal to the latitude of the location ( $38^{\circ}$ South). The electrical load $R_{L}$ was obtained by precision resistances, and the current was calculated on the basis of the measured voltage, where we accepted the error due to the resistances precision [44].

The silicon temperature was measured using thermocouples (type $\mathrm{T}$, copper-constantan) installed into little holes (red circles in Figure 9) made in the PET rear film of the panel. All of the measurement points were protected against light and air with a specific high reflective protective film. All data were collected every $30 \mathrm{~min}$ and stored for further calculations and ex-post processing. To take into account nonhomogeneous variations in the thermal field, five temperature sensors, suitably distributed, have been used. The silicon temperature time series are obtained by averaging the values of the five measurements. From the experimental point of view, the method is directly related to the silicon temperature of each panel. Furthermore, due to the specific geometric conformation of the system, justified by ratio thickness/surface close to $0.02 \mathrm{~m}^{-1}$, it is possible to neglect the thermal gradient across the panel itself.

\section{A New Correlation for the Photovoltaic Operating Temperature}

The authors, after a deep analysis of the experimental data, observed that, among the operating temperature of the PV panel, the outside weather conditions, and the electricity regime, the following empirical correlation exists:

$$
T_{c}=T_{a}+\frac{G}{\alpha+\beta \cdot W}+\gamma \cdot \ln \left(1+\frac{V}{V_{\text {mpp,panel }}\left(G, T_{c}\right)}\right),
$$

where $W$ is the wind speed $(\mathrm{m} / \mathrm{s})$ and the numerical values of the $\alpha, \beta$, and $\gamma$ parameters are three constants.

Equation (13) defines a new implicit correlation that takes into account the standard weather variables and the electricity production regimes of a PV panel in terms of the proximity to the maximum power points. The proximity to the maximum power points (that generally depends on solar irradiance and cell temperature) is estimated by means of the ratio $V / V_{\mathrm{mpp}}$. So, the essence of the method is to obtain the cell temperature taking into account the electricity 


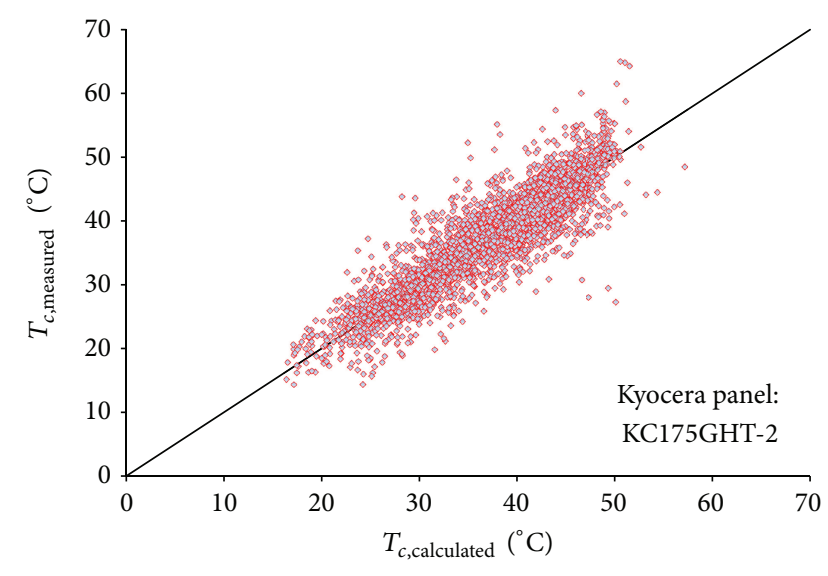

FIGURE 10: Kyocera panel operating temperature calculated with the novel correlation versus measured temperature.

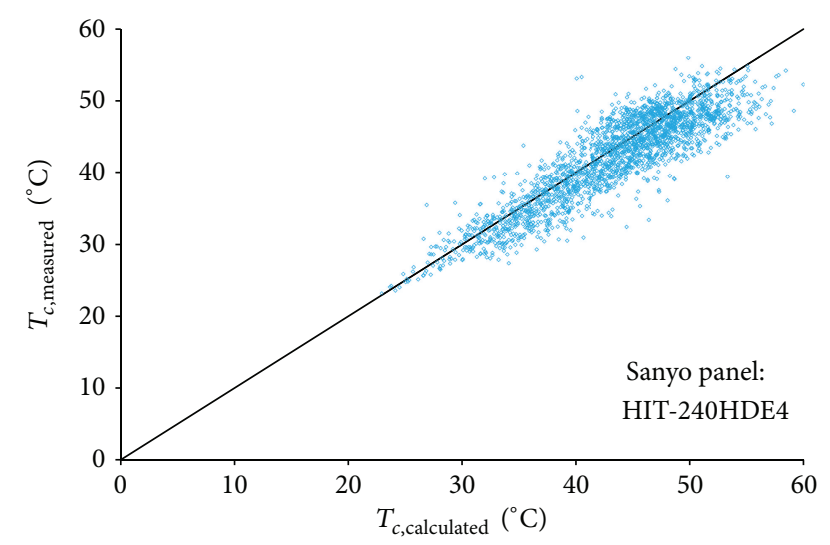

FIGURE 11: Sanyo panel operating temperature calculated with the novel correlation versus measured temperature.

production regime (measuring only $V$ ), the air temperature $T_{c}$, and solar irradiance $G$. The form of (13) has, therefore, a general validity. The specific characteristics of each panel are considered in (8) that provides an estimation of the $V_{\text {mpp }}$ in any condition of global irradiance and temperature.

In summary, given a set of experimental data, it is possible to predict the cell temperature versus voltage, air temperature, and global irradiance. The novelty of the proposed method is to consider the panel in real operating conditions by means of the generated voltage.

\section{Experimental Application}

The values of $\alpha, \beta$, and $\gamma$ were calculated using a large amount of data monitored in the field with the experimental
TABLE 3: Thermoelectrical features of the Sanyo HIT-240 HDE4.

\begin{tabular}{lcc}
\hline Maximum power & $P_{\max }(\mathrm{W})$ & 240 \\
Maximum voltage & $V_{\mathrm{mpp}}(\mathrm{V})$ & 35.5 \\
Maximum current & $I_{\mathrm{mp}}(\mathrm{A})$ & 6.77 \\
Open circuit voltage & $V_{\mathrm{oc}}(\mathrm{V})$ & 43.6 \\
Short circuit current & $I_{\mathrm{sc}}(\mathrm{A})$ & 7.37 \\
Thermal voltage coefficient & $\mu_{V_{\mathrm{oc}}}(\mathrm{V} / \mathrm{K})$ & -0.109 \\
Thermal current coefficient & $\mu_{I_{\mathrm{sc}}}(\mathrm{mA} / \mathrm{K})$ & 2.21 \\
\hline
\end{tabular}

apparatus previously described. More than 9000 data have permitted calculating the best fitting values in (7):

$$
\begin{aligned}
T_{c}= & T_{a}+\frac{G}{37.9862+3.13547 \cdot W} \\
& +2.57507 \cdot \ln \left[1+\frac{V}{V_{\text {mpp,panel }}\left(G, T_{c}\right)}\right],
\end{aligned}
$$

where $(\alpha ; \beta ; \gamma)=(37.09862 ; 3.13547 ; 2.57507)$; (14) represents the new implicit correlation able to calculate the operating temperature of any conventional flat Si-PV panel taking into account the regimen of electricity production thanks to presence of $V_{\text {mpp,panel }}\left(G, T_{c}\right)$.

To test its reliability, (14) was applied on two different panels: a polycrystalline and a monocrystalline panel. The experimental data presented in Figures 10 and 11 were collected using the monitoring system described above; data acquisition lasted for about three months in the spring of 2010; each data vector was acquired with a ten-minute time step. To allow modules to overcome the thermal transient at sunrise and at sunset, only data linked with a power output greater than $15 \mathrm{~W}$ (less than $10 \%$ of the nominal peak power) were used. No other filter was applied to original data.

Applying this procedure to the above-mentioned Kyocera panel, the plot of the measured $T_{c}$ values versus the values obtained from the above correlation in Figure 10 shows a very good relationship between the measured and calculated temperature cell data.

To better assess the reliability of the new proposed correlation, the authors tested the correlation on another monocrystalline PV panel (Sanyo HIT-240HDE4); see Table 3. At first the voltage at the maximum power point described by (12) was evaluated and the values $(a ; b)_{\text {Sanyo }}=$ $(0.003 ; 0.109)$ were calculated; then the thermal drift value was extracted by datasheet.

The results in Figure 11 show that even for the Sanyo panel there is a strong agreement between the real photovoltaic operating temperature and calculated values.

As already written, in the literature it is possible to find different correlations about the $T_{c}$ value [23] that permit evaluating the operating temperature cell knowing the same weather conditions and the thermoelectrical characteristics of a PV panel. The authors performed a comparison with some of the most known correlations [15-18, 45, 46] applying them to the database of 9000 experimental data points; in this 
TABLE 4: MAE results for different $T_{c}$ correlations.

\begin{tabular}{|c|c|c|c|}
\hline Correlation & $\begin{array}{c}\text { Kyocera } \\
\text { panel MAE (K) }\end{array}$ & $\begin{array}{c}\text { Sanyo } \\
\text { panel MAE (K) }\end{array}$ & Note \\
\hline$T_{c}=T_{a}+G /(\alpha+\beta \cdot W)+\gamma \cdot \ln \left[1+V / V_{\mathrm{mpp}}\left(G, T_{c}\right)\right]$ & 2.4 & 2.5 & $\begin{array}{c}\alpha=38.0385, \beta=3.15126 \\
\text { and } \\
\gamma=2.64173\end{array}$ \\
\hline$T_{c}=T_{a}+\alpha G\left(1+\beta T_{a}\right)(1-\gamma W)(1-1.053 \eta)[15]$ & 4.6 & 4.7 & $\begin{array}{c}W=1 \mathrm{~m} / \mathrm{s}, \alpha=0.0138 \\
\beta=0.031, \text { and } \gamma=0.042\end{array}$ \\
\hline$T_{c}=T_{a}+G(\tau \alpha / U)(1-\eta / \tau \alpha)[16,17]$ & 15.1 & 13.9 & $\tau \alpha / U$ taken as a constant \\
\hline$T_{c}=T_{a}+G(\tau \alpha-\eta) / U[18]$ & 15.3 & 16.8 & $\begin{array}{c}\tau \alpha / U \text { determined } \\
\text { experimentally }\end{array}$ \\
\hline
\end{tabular}

way it was possible to assess the quality of the new proposed correlation.

The results of this comparison are shown in Table 4 in which for each calculation procedure and for each panel was calculated the mean absolute error (MAE) between the measured and the calculated $T_{c}$ values as

$$
\text { MAE }=\frac{1}{N} \sum_{i=1}^{N}\left|T_{c, \text { measured }}-T_{c, \text { calculated }}\right|_{i},
$$

where $N$ is the number of available samples.

Table 4 shows that the new proposed correlation is characterised by a better MAE value compared with those ones from other correlations already published in the literature; more specifically, for the Kyocera panel, the MAE is $2.4 \mathrm{~K}$, and for the Sanyo panel, the MAE is $2.5 \mathrm{~K}$.

\section{Conclusions}

The authors presented a new implicit correlation to obtain the operative cell temperature from standard weather variables that takes into account the position of the working point of a PV panel. The analysis of the electrical characteristics (Figures 1 and 2) suggests that the $V / V_{\text {mpp,panel }}\left(G, T_{c}\right)$ ratio can be used to characterize the electricity production regimes of a PV panel. In this paper is suggested a relationship, represented by (12), that defines the $V_{\text {mpp,panel }}\left(G, T_{c}\right)$, typical for each panel. Indeed it is necessary to evaluate the value of $(a, b)$ parameters for each considered PV panel applying the leastsquares techniques at five $V_{\text {mpp }}$ points in correspondence of five values of insolation. Finally, on the basis of the hypothesis that the thermal balance of the panel depends not only on weather conditions but also on electricity production regimes summarized by the ratio $V / V_{\text {mpp }}$, the authors propose a new correlation to calculate the operative temperature $T_{c}$ represented by (13). In this implicit correlation $T_{c}$ depends on wind speed $W$, on insolation $G$, on the ratio $V / V_{\text {mpp,panel }}$ of the considered panel, and on the constant parameters $\alpha, \beta$, and $\gamma$.

Using a large database of monitored data from only one polycrystalline PV device, the authors evaluated the $\alpha, \beta$, and $\gamma$ parameters and their values are $\alpha=38.038, \beta=3.151$, and $\gamma=2.642$.

To assess the performance of this new implicit correlation and to ensure its general validity, the operating temperature was calculated on two different panels: monocrystalline and polycrystalline panels.

For greater clarity, all steps of the procedure are listed in the following:

(1) identification of the PV panel and its current thermal drift $\mu_{T}$

(2) determination of five $V_{\text {mpp }}$ points in correspondence of five values of insolation from datasheet;

(3) calculation of the $(a, b)$ parameters with the leastsquares techniques;

(4) evaluation of the $T_{c}$ value of the PV panel using (14).

As shown in the graphs in Figures 10 and 11, the prediction of $T_{c}$ values for different panels is very good. The MAE between the measured and estimated operating temperatures was extremely low for both panels. The good results obtained are due to the classification of the operating regimes of the solar panel summarized by the $V / V_{\text {mpp }}$ ratio, which represents a novelty in the field. Furthermore, a comparison with other common correlations, widely used and available in the literature, showed that the new correlation is a significant improvement in terms of MAE.

\section{Conflict of Interests}

The authors declare that there is no conflict of interests regarding the publication of this paper.

\section{References}

[1] R. Pernick, C. Wilder, and T. Winnie, Clean Energy Trends 2012, The Clean Edge, 2012.

[2] G. Ciulla, V. Lo Brano, and A. Orioli, "A criterion for the assessment of the reliability of ASHRAE conduction transfer function coefficients," Energy and Buildings, vol. 42, no. 9, pp. 1426-1436, 2010.

[3] G. Beccali, M. Cellura, V. L. Brano, and A. Orioli, "Is the transfer function method reliable in a European building context? A theoretical analysis and a case study in the south of Italy," Applied Thermal Engineering, vol. 25, no. 2-3, pp. 341-357, 2005.

[4] V. Franzitta and G. Rizzo, "Renewable energy sources: a mediterranean perspective," in Proceedings of the 2nd International Conference on Chemical, Biological and Environmental Engineering (ICBEE '10), pp. 48-51, Cairo, Egypt, November 2010. 
[5] M. Trapanese, V. Franzitta, and A. Viola, "Design and performance of a high temperature superconducting axial flux generator," IEEE Transactions on Magnetics, vol. 49, no. 7, pp. 4113-4115, 2013.

[6] OECD IEA, World Energy Outlook 2011, OECD International Energy Agency, Paris, France, 2011.

[7] M. Cellura, G. Ciulla, V. Lo Brano, A. Marvuglia, and A. Orioli, "A Photovoltaic panel coupled with a phase changing material heat storage system in hot climates," in Proceedings of the 25th Conference on Passive and Low Energy Architecture (PLEA '08), abstract number 582, 2008.

[8] M. Cellura, L. Campanella, G. Ciulla et al., "The redesign of an Italian building to reach net zero energy performances: a case study of the SHC Task 40-ECBCS Annex 52," ASHRAE Transactions, vol. 117, no. 2, pp. 331-339, 2011.

[9] M. Mattei, G. Notton, C. Cristofari, M. Muselli, and P. Poggi, "Calculation of the polycrystalline PV module temperature using a simple method of energy balance," Renewable Energy, vol. 31, no. 4, pp. 553-567, 2006.

[10] V. M. Andreev, V. A. Grilikhes, and V. D. Rumyantsev, Photovoltaic Conversion of Concentrated Sunlight, John Wiley \& Sons, London, UK, 1997.

[11] K. Emery, J. Burdick, Y. Caiyem et al., "Temperature dependence of photovoltaic cells, modules, and systems," in Proceedings of the 25th IEEE Photovoltaic Specialists Conference, pp. 1275-1278, Washington, DC, USA, May 1996.

[12] D. L. King and P. E. Eckert, "Characterizing (rating) the performance of large photovoltaic arrays for all operating conditions," in Proceedings of the 25th IEEE Photovoltaic Specialists Conference, pp. 1385-1388, Washington, DC, USA, May 1996.

[13] A. R. Wilshaw, J. R. Bates, and N. M. Pearsall, "Photovoltaic module operating temperature effects," in Proceedings of the Eurosun '96, pp. 940-944, Munich, Germany, 1996.

[14] S. Krauter, R. G. Araújo, S. Schroer et al., "Combined photovoltaic and solar thermal systems for facade integration and building insulation," Solar Energy, vol. 67, no. 4-6, pp. 239-248, 1999.

[15] J. M. Servant, "Calculation of the cell temperature for photovoltaic modules from climatic data," in Proceedings of the 9th Biennal Congress of ISES-Intersol 85, p. 370, Montreal, Canada, 1985.

[16] J. A. Duffie and E. A. Beckman, Solar Energy Thermal Processes, John Wiley \& Sons, Hoboken, NJ, USA, 3rd edition, 1991.

[17] G. N. Tiwari, Solar Energy: Fundamentals, Design, Modelling and Applications, Alpha Science, Pangbourne, UK, 2002.

[18] TRNSYS manual-type 194, Five-parameter module, Solar Energy Laboratory, University of Wisconsin-Madison.

[19] E. Skoplaki and J. A. Palyvos, "On the temperature dependence of photovoltaic module electrical performance: a review of efficiency/power correlations," Solar Energy, vol. 83, no. 5, pp. 614-624, 2009.

[20] D. L. Evans, "Simplified method for predicting photovoltaic array output," Solar Energy, vol. 27, no. 6, pp. 555-560, 1981.

[21] G. Notton, C. Cristofari, M. Mattei, and P. Poggi, "Modelling of a double-glass photovoltaic module using finite differences," Applied Thermal Engineering, vol. 25, no. 17-18, pp. 2854-2877, 2005.

[22] M. Koehl, M. Heck, S. Wiesmeier, and J. Wirth, "Modeling of the nominal operating cell temperature based on outdoor weathering," Solar Energy Materials and Solar Cells, vol. 95, no. 7, pp. 1638-1646, 2011.
[23] E. Skoplaki and J. A. Palyvos, "Operating temperature of photovoltaic modules: a survey of pertinent correlations," Renewable Energy, vol. 34, no. 1, pp. 23-29, 2009.

[24] D. Faiman, "Assessing the outdoor operating temperature of photovoltaic modules," Progress in Photovoltaics: Research and Applications, vol. 16, no. 4, pp. 307-315, 2008.

[25] J. W. Stultz, "Thermal and other tests of photovoltaic modules performed in natural sunlight," Journal of Energy, vol. 3, no. 6, pp. 363-372, 1979.

[26] S. Pace and M. Magni, "A new indoor procedure for the determination of NOCT," in Proceedings of the Photovoltaic Solar Energy Conference, vol. 5, pp. 667-671, 1984.

[27] M. K. Fuentes, “Thermal modeling of residential photovoltaic arrays," in Proceedings of the Photovoltaic Specialists Conference, vol. 17, pp. 1341-1346, May 1984.

[28] ASTM, Standard Test Methods for Electrical Performance of Non Concentrator Terrestrial Photovoltaic Modules and Arrays Using Reference Cells, Standard E1036, American Society for Testing and Materials, West Conshohocken, Pa, USA, 1998.

[29] J. Kuitche, J. Oh, A. Brunger et al., "One year NOCT RoundRobin testing per IEC 61215 standard," in Proceedings of the 37th IEEE Photovoltaic Specialists Conference (PVSC '11), pp. 23802385, Seattle, Wash, USA, June 2011.

[30] R. Bharti, J. Kuitche, and M. G. Tamizhmani, "Nominal operating cell temperature (NOCT): effects of module size, loading and solar spectrum," in Proceedings of the 34th IEEE Photovoltaic Specialists Conference (PVSC '09), pp. 1657-1662, Philadelphia, Pa, USA, June 2009.

[31] J. Sutterlueti, S. Ransome, R. Kravets, and L. Schreier, "Characterising PV modules under outdoor conditions: what's most important for energy yield," in Proceedings of the 26th European Photovoltaic Solar Energy Conference and Exhibition, pp. 36083614, 2008.

[32] V. Lo Brano, G. Ciulla, V. Franzitta, and A. Viola, "A novel implicit correlation for the operative temperature of a PV panel," AASRI Procedia, vol. 2, pp. 112-120, 2012.

[33] M. Karamirad, M. Omid, R. Alimardani, H. Mousazadeh, and S. N. Heidari, "ANN based simulation and experimental verification of analytical four-and five-parameters models of PV modules," Simulation Modelling Practice and Theory, vol. 34, pp. 86-98, 2013.

[34] D. Wijayasekara, M. Manic, P. Sabharwall, and V. Utgikar, "Optimal artificial neural network architecture selection for performance prediction of compact heat exchanger with the EBaLM-OTR technique," Nuclear Engineering and Design, vol. 241, no. 7, pp. 2549-2557, 2011.

[35] G. Ciulla, V. Lo Brano, and E. Moreci, "Forecasting the cell temperature of PV modules with an adaptive system," International Journal of Photoenergy, vol. 2013, Article ID 192854, 10 pages, 2013.

[36] M. Veerachary, T. Senjyu, and K. Uezato, "Neural-networkbased maximum-power-point tracking of coupled-inductor interleaved-boost-converter-supplied PV system using fuzzy controller," IEEE Transactions on Industrial Electronics, vol. 50, no. 4, pp. 749-758, 2003.

[37] J. Binfet and B. M. Wilamowski, "Microprocessor implementation of fuzzy systems and neural networks," in Proceedings of the International Joint Conference on Neural Networks (IJCNN '01), pp. 234-239, July 2001. 
[38] A. E. A. Nafeh, F. H. Fahmy, and E. M. Abou El-Zahab, "Evaluation of a proper controller performance for maximumpower point tracking of a stand-alone PV system," Solar Energy Materials and Solar Cells, vol. 75, no. 3-4, pp. 723-728, 2003.

[39] N. Patcharaprakiti, S. Premrudeepreechacharn, and Y. Sriuthaisiriwong, "Maximum power point tracking using adaptive fuzzy logic control for grid-connected photovoltaic system," Renewable Energy, vol. 30, no. 11, pp. 1771-1788, 2005.

[40] G. Ciulla, V. Lo Brano, V. Di Dio, and G. Cipriani, "A comparison of different one-diode models for the representation of I-V characteristic of a PV cell," Renewable and Sustainable Energy Reviews, vol. 32, pp. 684-696, 2014.

[41] V. Lo Brano and G. Ciulla, "An efficient analytical approach for obtaining a five parameters model of photovoltaic modules using only reference data," Applied Energy, vol. 111, pp. 894-903, 2013.

[42] IEC 891 Standard of Procedures for Temperature and Irradiance Corrections to Measured I-V Characteristics of Crystalline Silicon PV Devices.

[43] V. Lo Brano, A. Orioli, G. Ciulla, and S. Culotta, "Quality of wind speed fitting distributions for the urban area of Palermo, Italy," Renewable Energy, vol. 36, no. 3, pp. 1026-1039, 2011.

[44] E. Cardona and A. Piacentino, "A measurement methodology for monitoring a CHCP pilot plant for an office building," Energy and Buildings, vol. 35, no. 9, pp. 919-925, 2003.

[45] T. Hove, "A method for predicting long-term average performance of photovoltaic systems," Renewable Energy, vol. 21, no. 2, pp. 207-229, 2000.

[46] U. Eicker and A. Dalibard, "Photovoltaic-thermal collectors for night radiative cooling of buildings," Solar Energy, vol. 85, no. 7, pp. 1322-1335, 2011. 

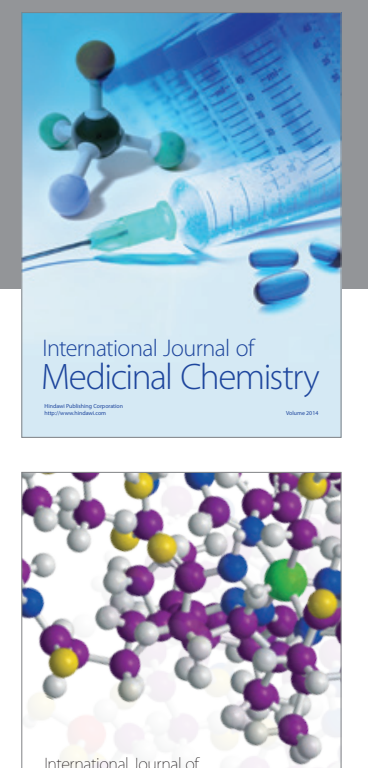

\section{Carbohydrate} Chemistry

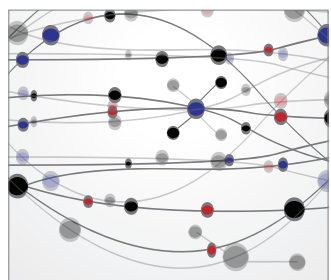

The Scientific World Journal
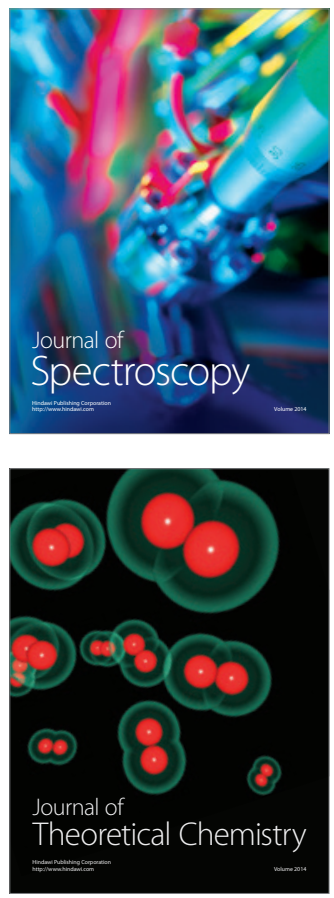
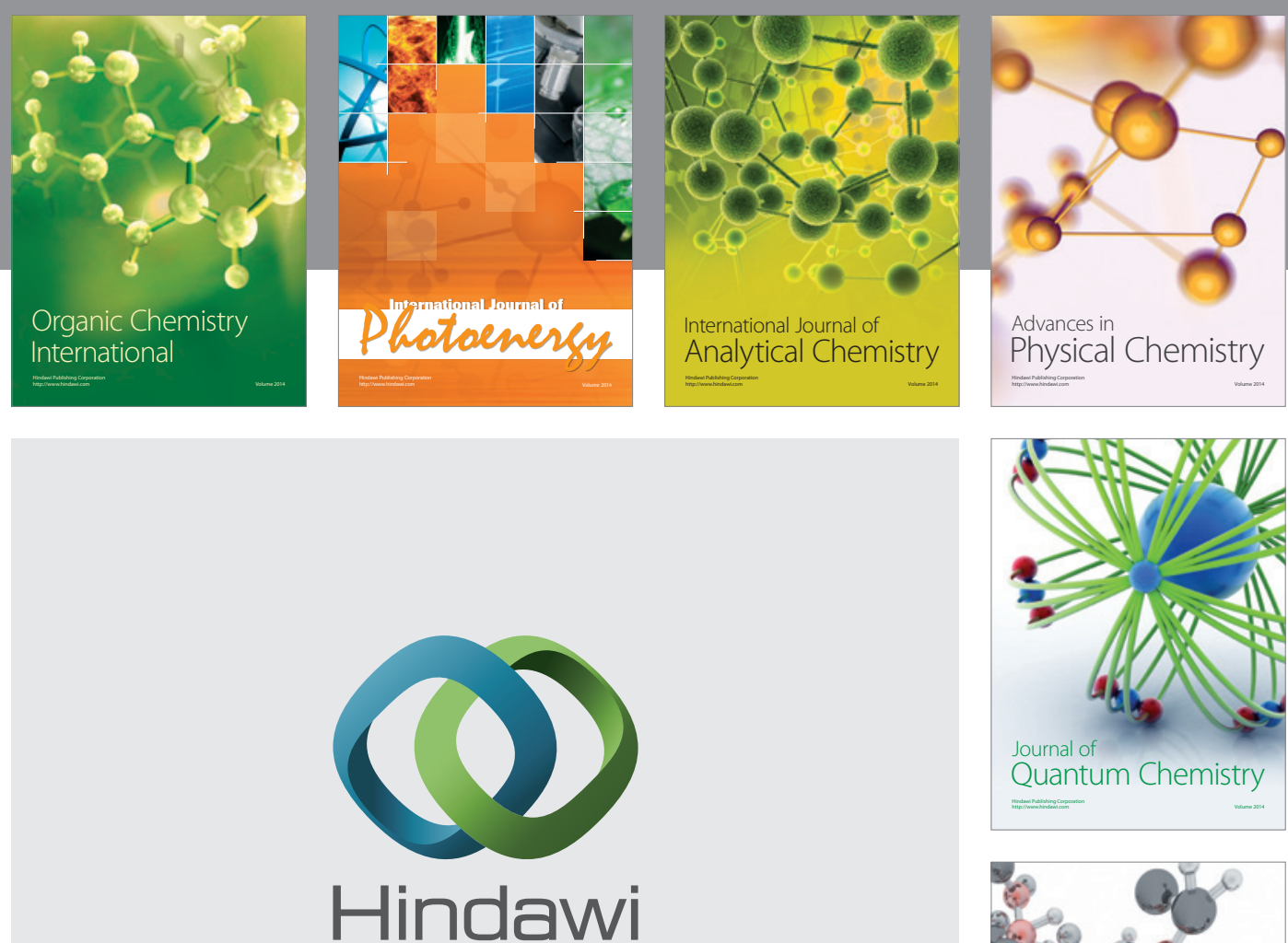

Submit your manuscripts at

http://www.hindawi.com

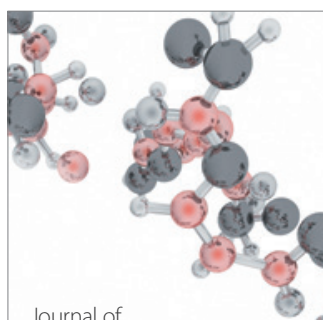

Analytical Methods

in Chemistry

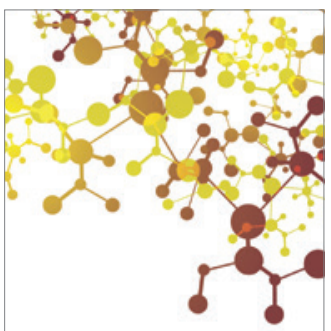

Journal of

Applied Chemistry

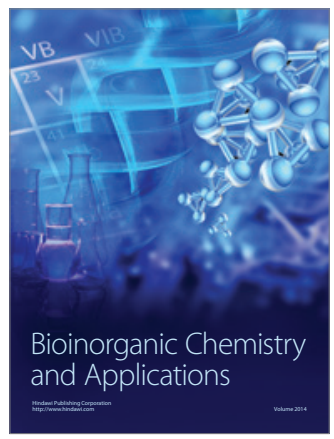

Inorganic Chemistry
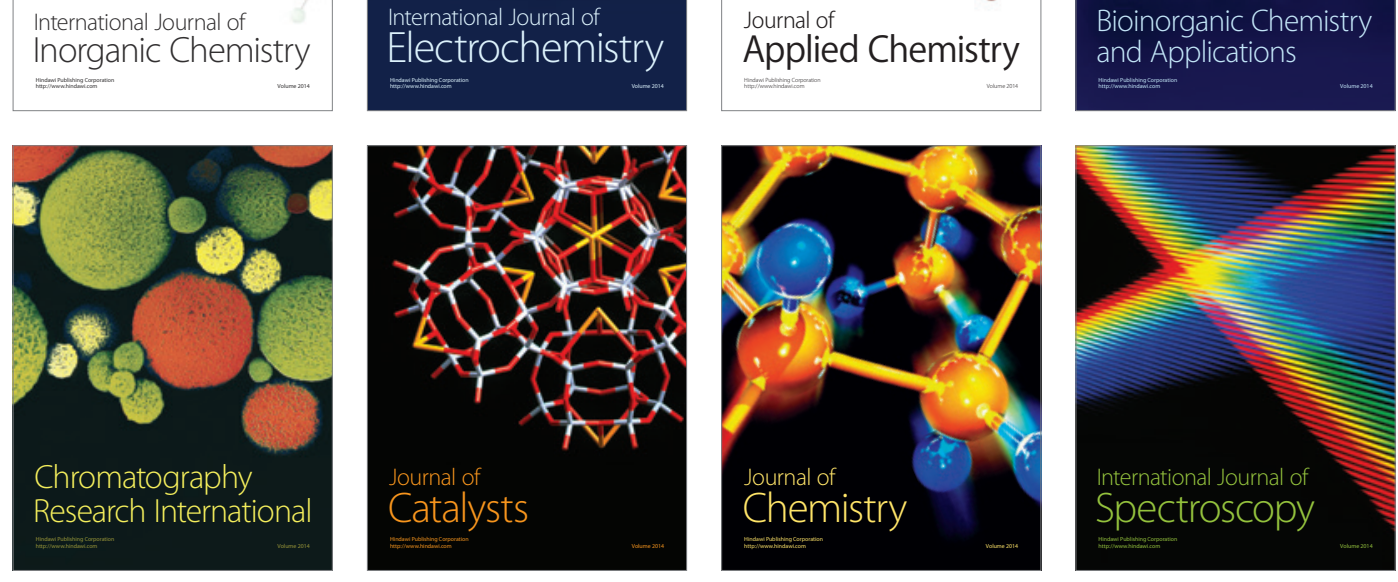